\title{
Patient reported outcomes in elective laparoscopic cholecystectomy
}

\author{
Malcolm H.W. Mak ${ }^{1}$, Woon Ling Chew ${ }^{2}$, Sameer P. Junnarkar ${ }^{1}$, Winston W.L. Woon ${ }^{1}$, \\ Jee-Keem Low ${ }^{1}$, Terence C.W. Huey ${ }^{1}$, and Vishalkumar G. Shelat ${ }^{1}$ \\ ${ }^{1}$ Department of General Surgery, Tan Tock Seng Hospital, ${ }^{2}$ School of Biological Sciences, \\ Nanyang Technological University, Singapore
}

\begin{abstract}
Backgrounds/Aims: Traditional outcome measures (e.g., length of hospital stay, morbidity, and mortality) are used to determine the quality of care, but these may not be most important to patients. It is unclear which outcomes matter to patients undergoing elective laparoscopic cholecystectomy (ELC). We aim to identify patient-reported outcome measures (PROM) which patients undergoing ELC valued most. Methods: A 45-item questionnaire with Four-point Likert-type questions developed from prior literature review, prospectively administered to patients treated with ELC at a tertiary institution in Singapore. Results: Seventy-five patients participated. Most essential factors were technical skill and experience level of a surgeon, long-term quality of life (QoL), patient involvement in decision-making, communication skill of a surgeon, cleanliness of the ward environment, and standards of nursing care. Least important factors were hospitalization leave duration, length of hospital stay, a family's opinion of the hospital, and scar cosmesis. Employed patients were more likely to find hospitalization leave duration $(p<0.001)$ and procedure duration $(p=0.042)$ important. Younger patients $(p=0.048)$ and female gender $(p=0.003)$ were more likely to perceive scar cosmesis as important. Conclusions: Patients undergoing ELC value long-term QoL, surgeon technical skill and experience level, patient involvement in decision-making, surgeon communication skill, cleanliness of the ward environment, and nursing care standards. Day-case surgery, medical leave, family opinion of hospital, and scar cosmesis were least important. Understanding what patients value will help guide patient-centric healthcare delivery. (Ann Hepatobiliary Pancreat Surg 2019;23:20-33)
\end{abstract}

Key Words: Cholecystectomy; Gallstones; Patient-reported outcomes; Cholecystolithiasis

\section{INTRODUCTION}

Gallstone disease is common in developed societies, affecting up to $10-15 \%$ of the population. ${ }^{1}$ While most patients remain asymptomatic, each year $1-2 \%$ of patients develop symptoms or complications. ${ }^{2}$ Laparoscopic cholecystectomy (LC) is the current gold standard for the treatment of symptomatic cholecystolithiasis. ${ }^{3}$ Traditional outcome measures such as hospital length of stay, 30-day readmission rates, cost and conversion rates are often measured as quality indicators of $\mathrm{LC}^{4,5}$ but it is unclear whether these outcomes are important to patients.

In the era of patient-centric and value-driven health care, it is essential to understand the needs of patients, so that healthcare providers and policymakers can align the goals to timely serve the patients' needs within evidence-based healthcare culture.

Various studies have used different outcome measurements after LC, such as the Surgical Outcomes Measurement System, ${ }^{6}$ Gastrointestinal Quality of Life Index (GIQLI), ${ }^{7-9}$ Patients' Experience of Surgery Questionnaire (PESQ), ${ }^{10}$ EuroQol-5D (EQ-5D) and condition-specific questionnaires. ${ }^{11}$ These studies highlighted the usefulness of patient-reported outcome measures (PROM) as significant determinants of patient satisfaction following cholecystectomy. The use of PROM provides a better measure of healthcare from the patient perspective and provides meaningful insights for both clinicians and healthcare administration

Received: June 29, 2018; Revised: September 21, 2018; Accepted: September 25, 2018

Corresponding author: Vishalkumar G. Shelat

Hepato-Pancreato-Biliary Surgery Service, Department of General Surgery, Tan Tock Seng Hospital, 11 Jalan Tan Tock Seng, 308433, Singapore Tel: +65 6357 7807, Fax: +65 6357 7809, E-mail: vishal_g_shelat@ttsh.com.sg

Copyright (C) 2019 by The Korean Association of Hepato-Biliary-Pancreatic Surgery

This is an Open Access article distributed under the terms of the Creative Commons Attribution Non-Commercial License (http://creativecommons.org/ licenses/by-nc/4.0) which permits unrestricted non-commercial use, distribution, and reproduction in any medium, provided the original work is properly cited. Annals of Hepato-Biliary-Pancreatic Surgery • pISSN: 2508-5778 - elSSN: 2508-5859 
managers. ${ }^{12,13}$ However, there currently exists no standard on the type of PROM that should be studied after LC.

The National Health Service (NHS) in the UK has PROM programmes for hip, knee, varicose veins, and hernia surgery but not for gallbladder surgery. ${ }^{14}$ There are reports of PROM surveys with a major determinant being a Quality of Life (QoL) tool. ${ }^{6,15}$ It is important to recognize that PROM incorporates symptom reporting, satisfaction with care, treatment satisfaction, economic impact and patient experience in addition to health-related QoL. QoL is a subjective, multifaceted tool to quantify the physical, social, spiritual and psychological domains of disease/therapy and QoL outcomes are a mere subset of PROM within its all-inclusive concept. ${ }^{16}$ Equating PROM data along with QoL data is inaccurate and introduces bias.

Parkin et al. developed a PROM survey by a combination of systematic literature review, pilot patient surveys and investigator views and in our opinion, their PROM survey for patients with acute gallstone pathology is the most updated, comprehensive and grounded on sound science. ${ }^{15}$ In patients with severe gallstone pathology, they have reported that long-term QoL was the most critical outcome measure to patients and day case surgery was the least essential. ${ }^{15}$ We have reported that index admission cholecystectomy restores QoL (measured with GIQLI) in patients with acute cholecystitis. ${ }^{9}$ It is possible that an acute pathology or an emergency surgery may influence patients' decision making. Furthermore, patient values are also influenced by socio-cultural and geopolitical aspects.

Hence, we aim to study PROM independent of a QoL tool among multi-ethnic Asian demographic profile of patients undergoing elective LC.

\section{MATERIALS AND METHODS}

\section{Data collection}

This prospective cohort study was conducted at Tan Tock Seng Hospital (TTSH), Singapore. Consecutive patients who underwent elective LC in our surgical unit between $7^{\text {th }}$ August 2017 and $31^{\text {st }}$ October 2017 were included. The indications for LC included biliary colic, previous pancreatitis, past cholecystitis, and previous cholangitis. Patients who underwent emergency cholecystectomy were excluded.
Following informed consent, patients who underwent elective LC were administered the 45-item PROM questionnaire. The questionnaire was administered on the first post-operative day in either day surgery ward or general inpatient ward. The survey was self-administered, and patients were given privacy and time to complete the survey. Patients were assisted if there were any difficulties in comprehending the questions or required translation from the written English language used for the survey. Patient identifiers were not collected for this study.

\section{Questionnaire development}

The PROM questionnaire comprised 45 multiple choice questions with single-answer and four-point Likert-type scale questions (refer Appendix 1). The first seven questions established the socio-demographic profile, including age group, gender, education level, marital status, employment status, ethnicity, and type of housing. The next two questions concerned health behaviors such as the exercise and smoking frequency. Subsequent questions identified important factors that patients valued the most regarding elective LC in different aspects, including the perception of surgery pre-procedure and post-procedure, hospital experience, and the expectations of the long-term outcomes after cholecystectomy. These were ranked using a fourpoint Likert scale with one being "least important" and four being "most important."

Socio-demographic profiles were adopted in accordance with the Singapore National Health Survey. ${ }^{17}$ Factors that patients valued regarding LC were drafted out after a review of the literature and adapted from a recent study by Parkins et al. on patients' perspectives on acute gallstones pathology. ${ }^{15}$ The questionnaire was reviewed by our hospital advisory panel which comprised of two doctors, two clinical research nurses and two patient associates before submission and approval by a separate independent committee (National Healthcare Group Domain Specific Review Board) to ensure the validity of the questionnaire-based survey form. The institutional ethics approval number for this study is $2017 / 00717$.

\section{Statistical analysis}

Likert-type scale questions were treated as ordinal variables and grouped into two categories "More Important" (ranked ' 3 ' or ' 4 ' on the survey) and "Less Important" 
(ranked ' 1 ' or '2') for statistical analysis. Mean scores were used to identify the top and lowest ranking factors. Statistical tests were performed using IBM SPSS (IBM SPSS Statistics Version 25 for Windows, Armonk, NY: IBM Corp.). To determine whether socio-demographic factors influence which factors were more important to patients, univariate analyses were performed using chisquare tests with a $p$-value of less than 0.05 used to indicate statistical significance.

\section{RESULTS}

\section{Patient cohort}

78 surveys were administered to patients who underwent elective LC from $7^{\text {th }}$ August 2017 to $31^{\text {st }}$ October 2017. Three $(3 / 78,3.8 \%)$ of these were incomplete and excluded from further analyses. Table 1 below shows the sociodemographic profile of the study population. The majority were female $(49,65.3 \%)$, between $41-60$ years of age $(37,49.3 \%)$, and employed (36, 48.0\%).

\section{Patient perceptions of surgery}

Fig. 1 below shows what patients perceived as most and least important aspects of the procedure and recovery process. The experience level of the surgeon was the most important factor with 74 out of 75 (98.7\%) patients ranking it as either very important or important. Other important factors were the technical skill of the surgeon (72, $96.0 \%$ ) and risk of severe complications (70, 93.3\%). The duration of hospitalization leave was the least important factor with 59 out of $75(78.7 \%)$ patients ranking it as either less important or least important. Other less important factors were day-case surgery $(58,77.3 \%)$, and duration of procedure $(32,42.7 \%)$. Patients who were employed were more likely to find the period of hospitalization leave $(p<0.001)$ and duration of procedure $(p=0.042)$ important. No socio-demographic factors were associated with whether patients perceived day-case surgery as important.

\section{Patient perceptions on hospital experience}

Fig. 2 demonstrates what patients perceived as most and least important aspects of their hospital experience. Patients' involvement in decision making, communication skill of the surgeon, cleanliness of the ward, operating theatre environment and standards of nursing care all ranked high in what patients perceive as important in the hospital experience $(73,97.3 \%)$. The cost of the hospital bill also ranked high in patients' concerns $(64,85.3 \%)$.

Table 1. Socio-demographic profile of patients surveyed

\begin{tabular}{|c|c|}
\hline Characteristic & n $(\%)$ \\
\hline \multicolumn{2}{|l|}{ Age group } \\
\hline $21-40$ years & $8(10.7)$ \\
\hline $41-60$ years & $37(49.3)$ \\
\hline $61-80$ years & $29(38.7)$ \\
\hline$>80$ years & $1(1.3)$ \\
\hline \multicolumn{2}{|l|}{ Sex } \\
\hline Male & $26(34.7)$ \\
\hline Female & $49(65.3)$ \\
\hline \multicolumn{2}{|l|}{ Highest education level } \\
\hline Primary education or less & $19(25.3)$ \\
\hline Secondary education & $30(40.0)$ \\
\hline Diploma & $19(25.3)$ \\
\hline Degree & $4(5.3)$ \\
\hline Postgraduate degree & $3(4.0)$ \\
\hline \multicolumn{2}{|l|}{ Marital status } \\
\hline Single & $13(17.3)$ \\
\hline Married & $58(77.3)$ \\
\hline Widowed & $2(2.7)$ \\
\hline Divorced or separated & $2(2.7)$ \\
\hline \multicolumn{2}{|l|}{ Employment status } \\
\hline Unemployed & $3(4.0)$ \\
\hline Self-employed & $7(9.3)$ \\
\hline Working/Employed & $36(48.0)$ \\
\hline Student & $1(1.3)$ \\
\hline Retired & $17(22.7)$ \\
\hline Homemaker & $11(14.7)$ \\
\hline \multicolumn{2}{|l|}{ Ethnicity } \\
\hline Chinese & $55(73.3)$ \\
\hline Malay & $8(10.7)$ \\
\hline Indian & $5(6.7)$ \\
\hline Others & $7(9.3)$ \\
\hline \multicolumn{2}{|l|}{ Housing type } \\
\hline 1 to 3 -room flat & $14(18.7)$ \\
\hline 4-room flat & $28(37.3)$ \\
\hline 5-room flat & $18(24.0)$ \\
\hline Executive flats and others & $3(4.0)$ \\
\hline Condominium and private flats & $5(6.7)$ \\
\hline Landed property & $4(4.3)$ \\
\hline Others & $3(4.0)$ \\
\hline \multicolumn{2}{|l|}{ Smoking } \\
\hline Current smoker & $7(9.3)$ \\
\hline Never smoker & $61(81.3)$ \\
\hline Previous smoker & $7(9.3)$ \\
\hline \multicolumn{2}{|l|}{ Exercise frequency } \\
\hline Regular & $19(25.3)$ \\
\hline Occasional & $39(52.0)$ \\
\hline Never & $17(22.7)$ \\
\hline
\end{tabular}




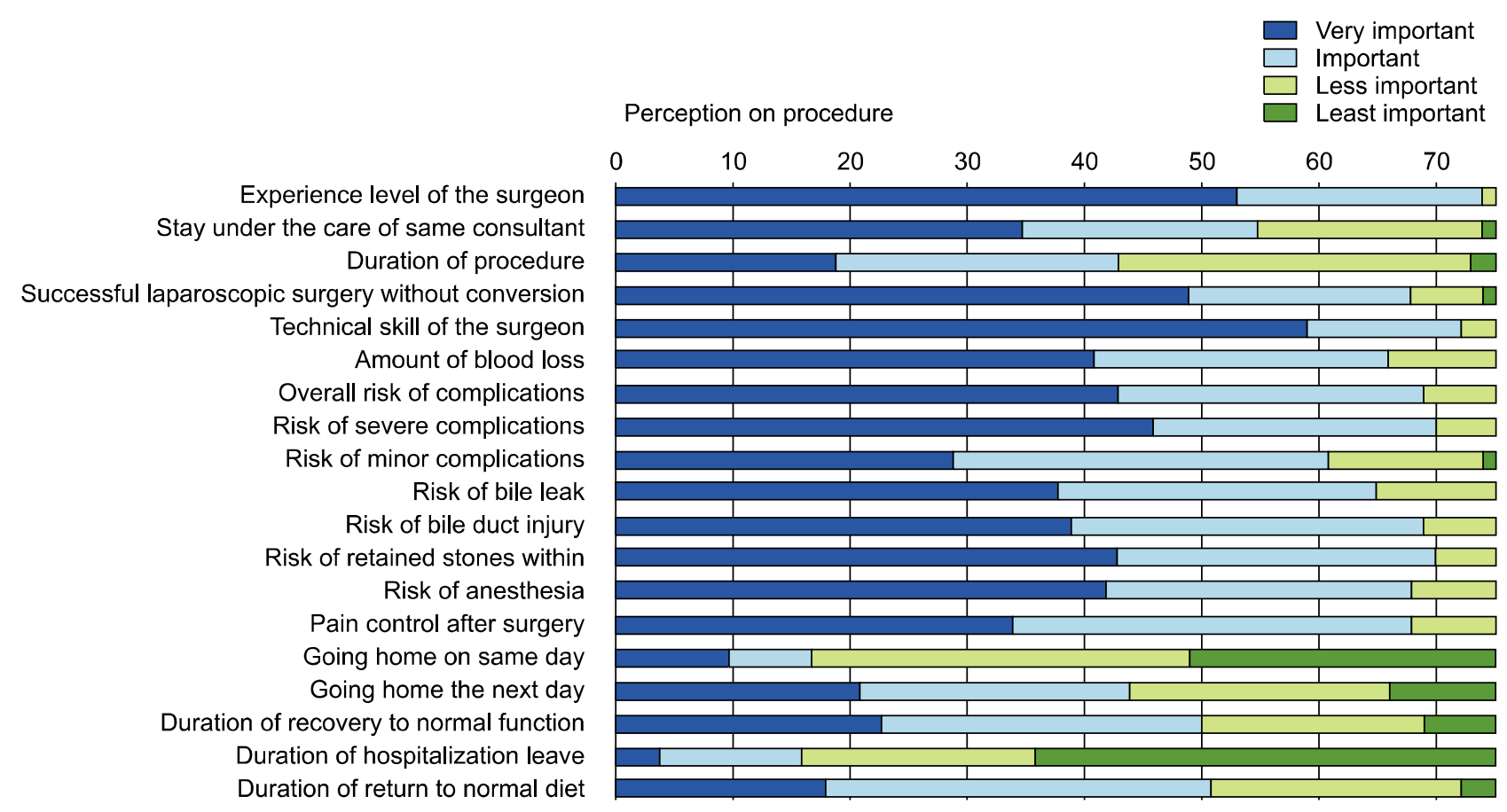

Fig. 1. Patient perception on the procedure.

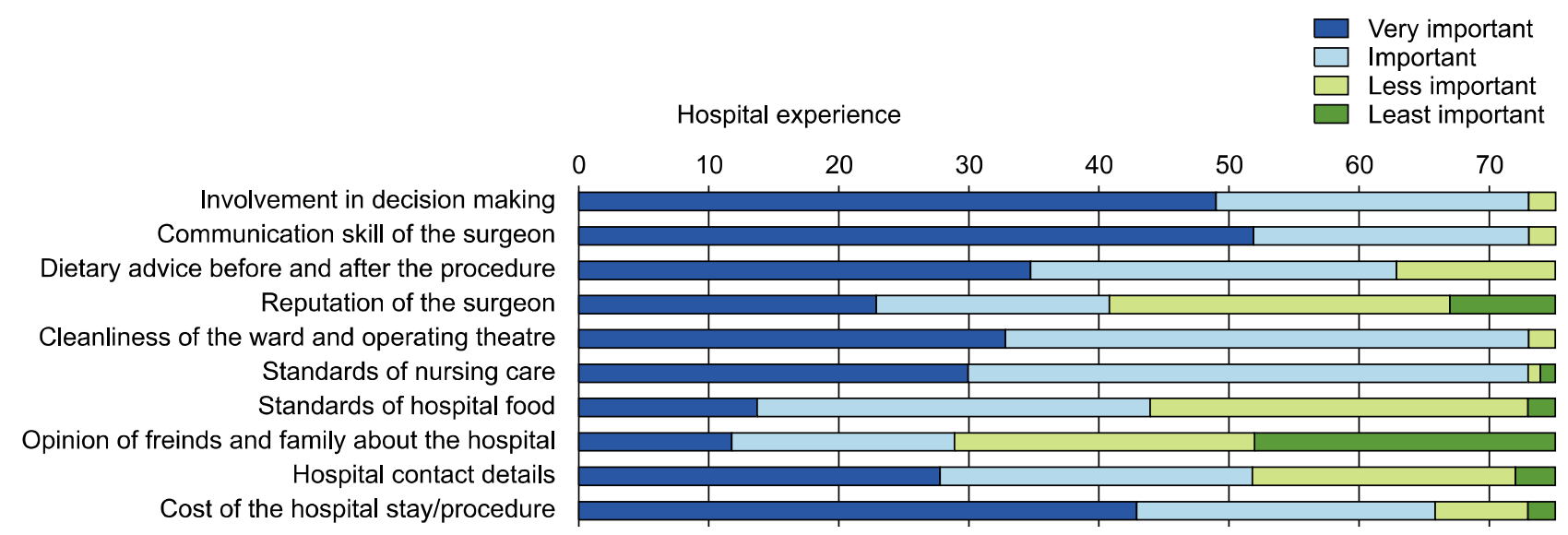

Fig. 2. Patient perception on the hospital experience.

Patients were less concerned about their friends' and families' opinion of the hospital $(46,61.3 \%)$ and reputation of the surgeon $(34,45.3 \%)$. No socio-demographic factors were associated with what patients perceive as important in the hospital experience. Patients' perspectives on waiting time for the surgery were also surveyed.

Approximately half $(40,53.3 \%)$ preferred as soon as the doctor can do, while a third $(28,37.3 \%)$ favored as soon as possible. The remaining $(7,9.3 \%)$ did not find the waiting time important. Most patients (67, 89.3\%) waited 8 weeks or less for their scheduled surgery from the date of consultation, while five $(6.7 \%)$ waited between 8 to 12 weeks and three $(4.0 \%)$ waited more than 12 weeks.

\section{Long-term outcomes}

Fig. 3 shows what patients perceived as most important regarding the long-term outcome of the surgery. QoL after surgery was the most important (74, 98.7\%), while scar cosmesis was the least important $(37,49.3 \%)$. Younger patients $(p=0.048)$ and female gender $(p=0.003)$ were more likely to perceive scar cosmesis as important. 

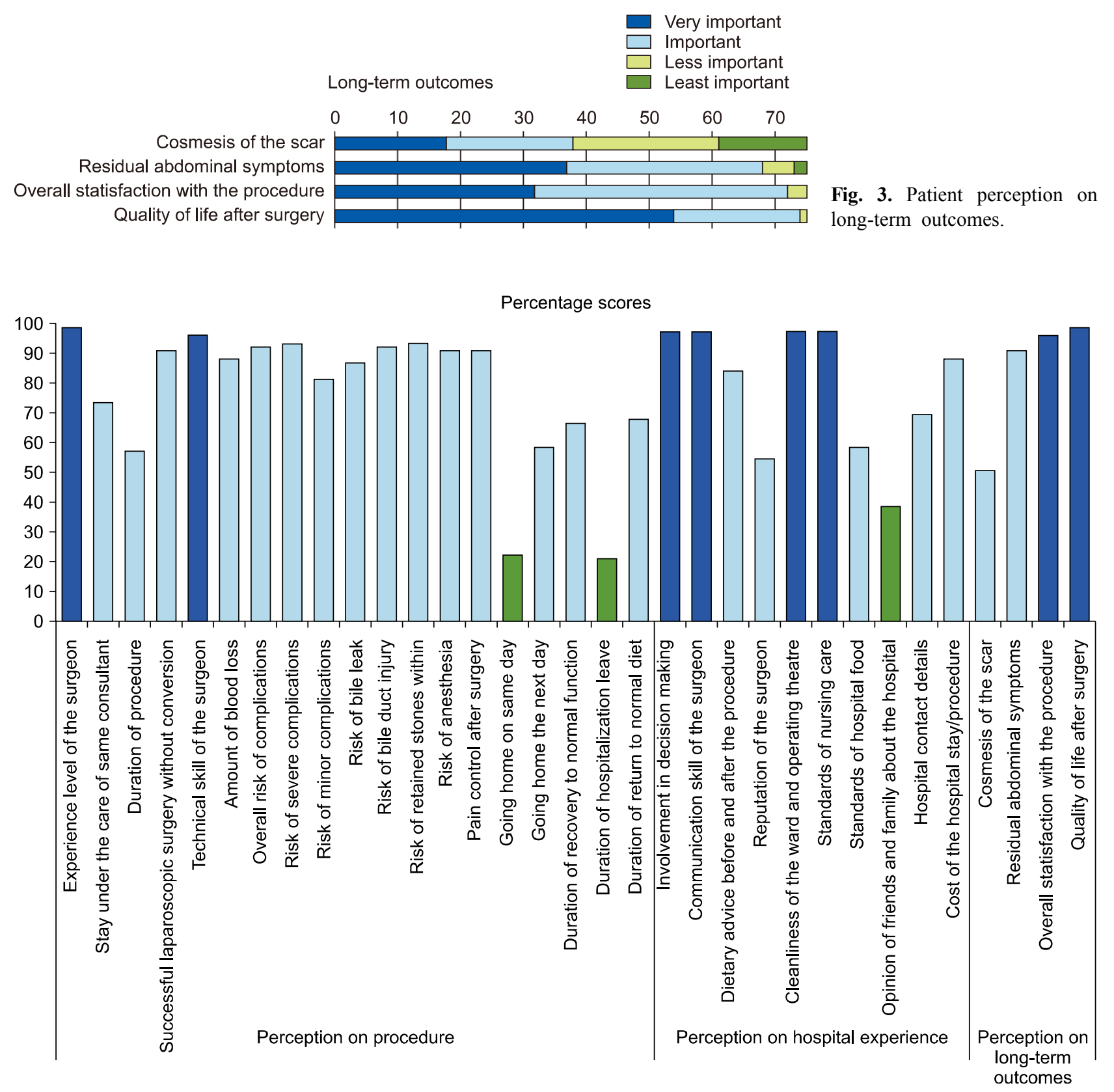

Fig. 4. Percentage scores of what patients value the most. Top ranking factors are highlighted in dark blue. Lowest three ranking factors are highlighted in green.

\section{Overall patient perceptions}

Fig. 4 shows the percentage scores of what patients valued the most out of all factors surveyed. The top-ranking factors were: experience level of the surgeon and quality of life after surgery $(98.7 \%)$, followed by patient involvement in decision making, communication skill of the surgeon, cleanliness of the ward and operating theatre, standards of nursing care $(97.3 \%)$ and technical expertise of the surgeon and overall satisfaction of the procedure $(96.0 \%)$. The lowest three ranking factors were: duration of hospitalization leave $(21.3 \%)$, going home the same day $(22.7 \%)$, and opinion of friends and family about the hospital (38.7\%). Scar cosmesis ranked as the fourth least important factor $(50.7 \%)$.

\section{DISCUSSION}

Our study has shown that surgeon experience, and long-term QoL are the most important factors for patients undergoing elective LC. Other important factors include 
shared decision making, communication skill of the surgeon, cleanliness of the hospital environment and standards of nursing care. The least important factors were going home on the same day (i.e., day-case surgery), duration of hospitalization leave, scar cosmesis, and reputation of the hospital. These findings are similar to a study by Parkin et al., ${ }^{15}$ which found that patients with acute gallstone pathology valued long-term QoL most and day-case surgery the least. Dauser et al. also found patients appreciated surgeons' experience more than cosmesis or length of hospital stay. ${ }^{18}$

'Nothing about me without me' is the primary pillar of a patient-centric healthcare system. Patients undergoing elective LC highly prioritizes QoL and this supports continued use of QoL as an important end-point in clinical trials. ${ }^{16}$ This study supports the view that QoL is vital to patients as much as in benign pathologies as malignant diseases. The GIQLI ${ }^{19}$ is one of the most widely used questionnaires for the objective measurement of QoL in gastrointestinal surgery, and its use is validated in gallstone disease. ${ }^{9,20}$ The European Association for Endoscopic Surgery (EAES) also recommends the GIQLI questionnaire for the evaluation of QoL for gallbladder disease ${ }^{21}$; it should, thus, be utilized as an vital outcome measure for future studies on cholecystectomy.

We have measured GIQLI in patients with acute cholecystitis and shown that index admission cholecystectomy restores GIQLI. ${ }^{9}$ It is possible that acute pathology and urgency of care may influence patient views and confound the outcome measures and hence a study on PROM in an elective setting was conducted. A PROM study in an elective situation helps extract unbiased opinions from patients with regards to outcomes related to the healthcare environment, waiting time, the experience level of doctor, early discharge, etc. and hence our study excluded patients undergoing emergency surgery.

Besides QoL, patient involvement in the decision making and communication skill of the surgeon were also highlighted as important factors by patients. With increasing awareness of patient-centric and personalized care delivery process, respecting patient autonomy and considering their views and choices are important in treatment planning. Hospital patient satisfaction surveys such as the Picker Patient Experience Questionnaire ${ }^{22}$ and similar tools are increasingly being reported to understand the health- care needs and provide a focused care relevant to individual needs. There is currently no standardized system of measure for patient experience and studies like ours are necessary to understand the patient's needs. ${ }^{23}$

The shared decision-making model involves two-way information exchange between patient and physician and a consensus management plan is formulated, accounting for the patient's values and priorities and upholds the primary ethical principle of patient autonomy. The shared decision-making model has shown to enhance patient compliance and improve QoL in oncology patients. ${ }^{24}$ Nontechnical skills are increasingly recognized as critical in surgical training and communication is the foundation on which the doctor-patient relationship is built.

This relationship of trust and mutual respect is an essential pillar and major determinant of PROM. Our study has also shown that patients prefer a senior doctor to perform their surgery. This is similar to a local decade-old survey reporting on patients undergoing elective orthopaedic and reconstructive procedures. ${ }^{25}$ They reported higher education status to be associated with a reluctance to let trainees perform procedures and our study shows technical skill and experience of surgery as amongst the top priorities by almost all patients.

In the era of minimal access surgery, there is an increasing move towards minimizing the size and number of incisions as it is often thought that these are what patients preferred. Hence novel techniques such as the Single Incision Laparoscopic Surgery (SILS) or robotic single-site cholecystectomy (RSSC) are increasingly seen as essential and relevant to patient needs. While SILS cholecystectomy is associated with better cosmesis and post-operative pain, ${ }^{26}$ there is an increased risk of an incisional hernia, and some trials have failed to demonstrate a difference in QoL, despite being a more costly procedure. ${ }^{27}$ Our study shows that scar cosmesis is not a high priority outcome for patients and future clinical trials to evaluate these newer surgical techniques should focus on the improvement in QoL rather than cosmesis and body image scores. However, younger and female patients are more likely to perceive scar cosmesis as vital, and this should be taken into consideration in a shared decision-making process.

Our PROM survey is critical as it not only considers the illness and medical therapy related outcomes; but also, 
the healthcare environment and the process of care delivery. Cleanliness of the hospital and ward environment was highly essential to patients, a finding similar to Parkin et al. ${ }^{15}$ Hospital cleanliness is a crucial component in infection control, ${ }^{28}$ with enhanced environmental cleaning reducing the levels of bacterial contamination and rates of methicillin-resistant staphylococcus aureus (MRSA) infections. ${ }^{29}$ Patients' perceptions of hospital cleanliness are also correlated with MRSA rates in some centers, ${ }^{30}$ and this should be taken into account by hospital management and policy-makers.

The standards of nursing care also ranked highly in what patients perceive as important and systems that allow performance evaluation of nursing care should be considered. $^{31}$ To minimize the risk of associated healthcare infections, early discharges are encouraged, healthcare institutions increasingly embrace day surgery with additional benefits of potential cost savings.

Day-case LC is widely adopted globally, and day-case surgery rates are also used as a quality indicator by some studies. $^{32}$ While an audit at our institution found that it is a worthwhile consideration, ${ }^{33}$ our survey shows that it is least important to our patients. This may be due to a lack of awareness that day-case LC has been shown to be safe, feasible and cost-effective. ${ }^{34,35}$ Our study is not designed to identify the barriers to day-surgery initiatives, but it reinforces the fact that patients are unlikely to be willing to be discharged on the same day. One possible reason is that the cost advantage of day-case LC compared with an overnight stay was not significant in our institution, and this echoes the current widely prevalent local practise of patients staying one night in the hospital under the ambulatory surgery 23 hours (AS 23) system. Parkin et al. also observed that day-case surgery was not critical to patients and we believe that such views are not merely a cultural-demographic attribute. ${ }^{15}$ However, a limitation in our study is that patients complete the survey a day after the procedure, which may introduce bias as they had already accepted the plan for an overnight stay in the hospital and hence do not value same-day return home after surgery. Nonetheless, patient education, improving health literacy and raising awareness about the safety of day surgery protocols are important initiatives that need to be driven by clinicians with patient engagement.

The cost of the hospital bill also ranked highly in pa- tients' concerns in the hospital experience, although it was not a top-ranking factor. This finding was not surprising, given Singapore's tiered co-payment structure in healthcare. While healthcare costs are escalating, patients may not be aware of the real healthcare costs due to government subsidies of up to $80 \%$ and the use of mandatory healthcare savings such as Medisave for hospital bill payment. Although this reduces the out-of-pocket payment for patients, it does not eliminate it entirely and hence patients were still concerned with the hospital bill. With inflating healthcare costs, it is worthwhile for doctors and policymakers to consider how to reduce hospital costs while maintaining the standard of care. A study at our institution for the treatment of acute cholecystitis found significant cost advantage of early LC over interval LC, predominantly due to the reduced hospital length of stay and investigation costs. ${ }^{36}$ Similar findings were reported in the UK by Sutton et al. for acute gallbladder pathologies, including biliary colic, acute cholecystitis, and gallstone pancreatitis, favouring emergent over delayed LC. ${ }^{37}$ From a healthcare provider perspective, it is worth looking into measures to increase the rate of early or emergent LC for such cases, to eventually pass on these healthcare savings to patients. Waiting time was not a significant factor for patients at our institution, likely because most patients were able to be scheduled for elective LC within eight weeks from the date of consultation.

Overall, our study highlights the essential elements of different priorities among the stakeholders in healthcare delivery and how they can be aligned to deliver patientcentric healthcare (Fig. 5). Understanding the patient's needs and values by PROM is the first step towards promotion of patient-centric healthcare service delivery. It is possible to reduce the gaps and improve the alignment of views and thoughts of all the three stakeholders with an enhanced understanding of patient needs, physician views and policy-maker decisions.

The strength of this study was that it utilized a comprehensive 45-item questionnaire with items comparable to existing literature, incorporating views across different aspects of the patients' perspective. We also achieved a high response rate $(75 / 78,96.2 \%)$, reducing nonresponse bias. The main limitations are that the questionnaire was administered to patients undergoing elective LC. The results are not applicable to patients undergoing emergency cho- 


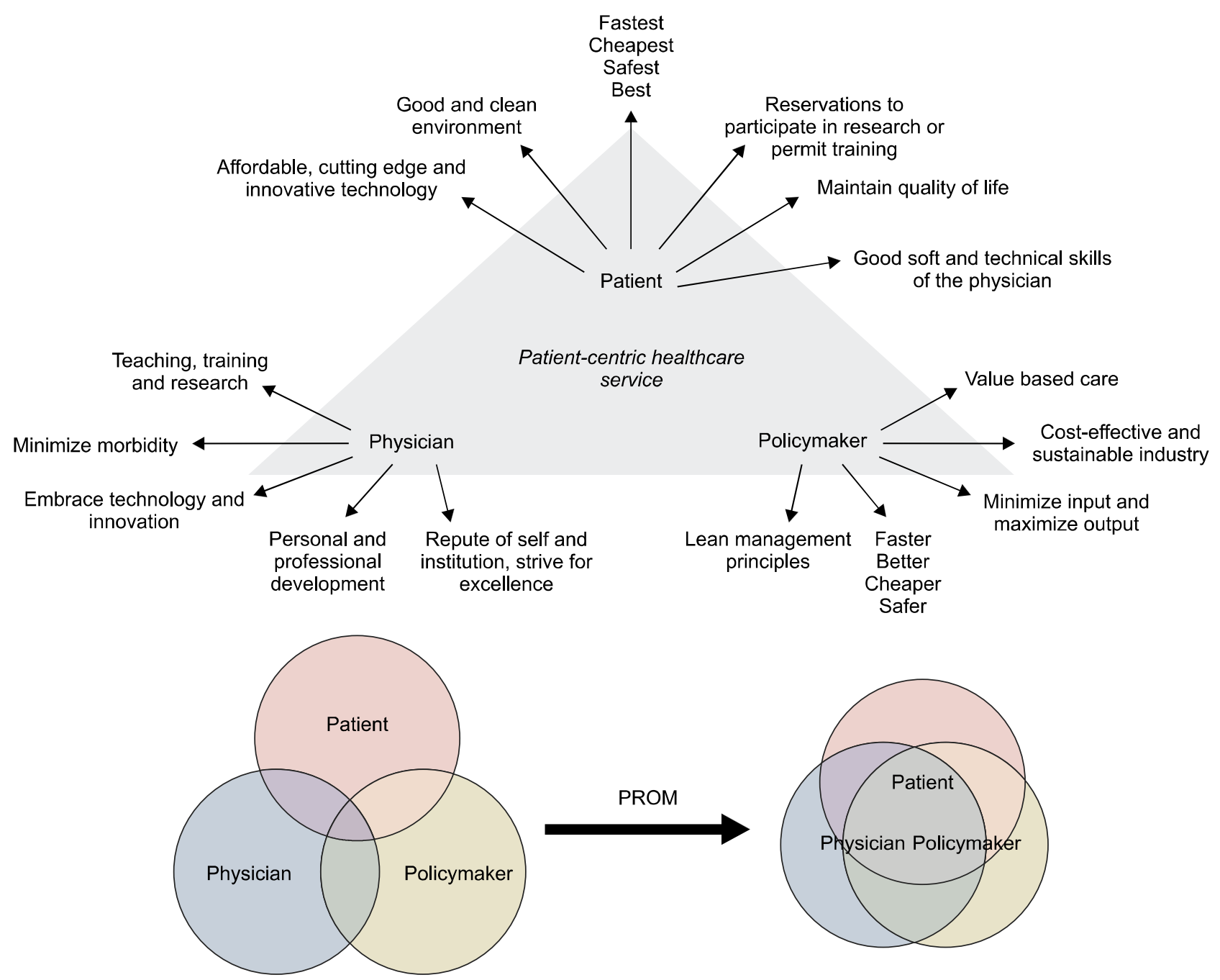

Fig. 5. Priorities of healthcare stakeholders and potential conflicts. PROM, Patient Reported Outcome Measures.

lecystectomy. In our institution, an estimated $600 \mathrm{LC}$ are performed annually, out of which approximately 120 to 130 are emergency cholecystectomies. ${ }^{38}$ This survey was also administered to patients only after the procedure. Thus their postoperative recovery state may affect their opinion and perception. However, it is essential that patient undergoes the procedure so he or she can share the experience and hence pre-procedure survey forms will have limited utility in clinical practice.

Further, conducting a post-procedure survey would consider the impact of post-operative adverse events on the outcomes. Conducting only one PROM survey on the first post-operative day and no follow-up PROM could be considered a limitation of our study. However, conducting a second PROM survey at follow-up will entail the need for additional resources with the risk of recall bias and mini- mal gain in the low morbidity elective LC procedure, and hence it was not performed.

Lastly, using a four-point Likert scale is not a standard norm as it enforces patient in committing a response they may not wish to commit or are not comfortable. Lozano et al. reported that reducing the response options to less than four reduces the reliability and validity of the scale and increasing the response options beyond seven rarely increases the psychometric properties, with the ideal between four and seven. ${ }^{39}$ The phrasing of our Likert responses was modified to ensure that a 'neutral' response is not applicable in the context.

PROM is a vital indicator of healthcare from the patient perspective and aligns patients' needs, physician views and policymaker decisions. Patients undergoing elective LC value both surgeon experience level and long-term 
quality of life the most. Patient involvement in decision making, communication skill of the surgeon, cleanliness of the ward and operating theatre, and standards of nursing care were also highly valued. Day-case surgery, length of hospitalization leave, the opinion of friends and family about the hospital, and cosmesis of the scar were the least important. These factors should be considered and monitored in the evaluation of patient-centric healthcare delivery systems and quality improvement initiatives.

\section{REFERENCES}

1. Stinton LM, Shaffer EA. Epidemiology of gallbladder disease: cholelithiasis and cancer. Gut Liver 2012;6:172-187.

2. Friedman GD. Natural history of asymptomatic and symptomatic gallstones. Am J Surg 1993;165:399-404.

3. Hassler KR, Jones MW. Gallbladder, cholecystectomy, laparoscopic. In: StatPearls. Treasure Island: StatPearls Publishing, 2017.

4. Harboe KM, Bardram L. The quality of cholecystectomy in Denmark: outcome and risk factors for 20,307 patients from the national database. Surg Endosc 2011;25:1630-1641.

5. Müller BP, Holzinger F, Leepin H, Klaiber C. Laparoscopic cholecystectomy: quality of care and benchmarking. Results of a single-institution specialized in laparoscopy compared with those of a nationwide study in Switzerland. Surg Endosc 2003; 17:300-305.

6. Zapf M, Denham W, Barrera E, Butt Z, Carbray J, Wang C, et al. Patient-centered outcomes after laparoscopic cholecystectomy. Surg Endosc 2013;27:4491-4498.

7. Lamberts MP, Den Oudsten BL, Gerritsen JJ, Roukema JA, Westert GP, Drenth JP, et al. Prospective multicentre cohort study of patient-reported outcomes after cholecystectomy for uncomplicated symptomatic cholecystolithiasis. Br J Surg 2015; 102:1402-1409.

8. Wanjura V, Sandblom G. How do quality-of-life and gastrointestinal symptoms differ between post-cholecystectomy patients and the background population? World J Surg 2016;40: 81-88.

9. Yu H, Chan EE, Lingam P, Lee J, Woon WWL, Low JK, et al. Index admission laparoscopic cholecystectomy for acute cholecystitis restores Gastrointestinal Quality of Life Index (GIQLI) score. Ann Hepatobiliary Pancreat Surg 2018;22:58-65.

10. Wennmacker S, Lamberts M, Gerritsen J, Roukema JA, Westert G, Drenth J, et al. Consistency of patient-reported outcomes after cholecystectomy and their implications on current surgical practice: a prospective multicenter cohort study. Surg Endosc 2017;31:215-224.

11. McLean KA, Sheng Z, O'Neill S, Boyce K, Jones C, Wigmore $\mathrm{SJ}$, et al. The influence of clinical and patient-reported outcomes on post-surgery satisfaction in cholecystectomy patients. World J Surg 2017;41:1752-1761.

12. Weldring T, Smith SM. Patient-Reported Outcomes (PROs) and Patient-Reported Outcome Measures (PROMs). Health Serv Insights 2013;6:61-68.

13. Delvin NJ, Appleby J, Buxton M. Getting the most out of PROMs: putting health outcomes at the heart of NHS decision-making. London: King's Fund, 2010.

14. NHS Digital. Finalised Patient Reported Outcome Measures (PROMs) in England - April 2015 to March 2016 [Internet].
NHS Digital 2017 [cited 2018 Jan 1]. Available from: https:// digital.nhs.uk/catalogue/PUB30036.

15. Parkin E, Stott M, Brockbank J, Galloway S, Welch I, Macdonald A. Patient-reported outcomes for acute gallstone pathology. World J Surg 2017;41:1234-1238.

16. Ahmed S, de Souza NN, Qiao W, Kasai M, Keem LJ, Shelat VG. Quality of life in hepatocellular carcinoma patients treated with transarterial chemoembolization. HPB Surg 2016;2016: 6120143.

17. Ministry of Health (Singapore). National Health Survey 2010 [Internet]. Singapore: Ministry of Health (Singapore) 2011 [cited 2017 Dec 28]. Available from: https://www.moh.gov.sg/content/moh_web/home/Publications/Reports/2011/national_health_s urvey2010.html.

18. Dauser B, Görgei A, Stopfer J, Herbst F. Conventional laparoscopy vs. single port surgery from a patient's point of view: influence of demographics and body mass index. Wien Klin Wochenschr 2012;124:834-841.

19. Eypasch E, Williams JI, Wood-Dauphinee S, Ure BM, Schmülling C, Neugebauer E, et al. Gastrointestinal Quality of Life Index: development, validation and application of a new instrument. $\mathrm{Br}$ J Surg 1995;82:216-222.

20. Sandblom G, Videhult P, Karlson BM, Wollert S, Ljungdahl M, Darkahi B, et al. Validation of Gastrointestinal Quality of Life Index in Swedish for assessing the impact of gallstones on health-related quality of life. Value Health 2009;12:181-184.

21. Korolija D, Sauerland S, Wood-Dauphinée S, Abbou CC, Eypasch E, Caballero MG, et al. Evaluation of quality of life after laparoscopic surgery: evidence-based guidelines of the European Association for Endoscopic Surgery. Surg Endosc 2004;18:879-897.

22. Jenkinson C, Coulter A, Bruster S. The Picker Patient Experience Questionnaire: development and validation using data from inpatient surveys in five countries. Int J Qual Health Care 2002;14: 353-358.

23. Al-Abri R, Al-Balushi A. Patient satisfaction survey as a tool towards quality improvement. Oman Med J 2014;29:3-7.

24. Tattersall MH, Butow PN, Clayton JM. Insights from cancer patient communication research. Hematol Oncol Clin North Am 2002;16:731-743.

25. Goh LW, Lim AY. Surgical training in Singapore: will patients consent to trainee surgeons performing their operations? Ann Acad Med Singapore 2007;36:995-1002.

26. Haueter R, Schütz T, Raptis DA, Clavien PA, Zuber M. Meta-analysis of single-port versus conventional laparoscopic cholecystectomy comparing body image and cosmesis. Br J Surg 2017; 104:1141-1159.

27. Rosenmüller MH, Nilsson E, Lindberg F, Åberg SO, Haapamäki MM. Costs and quality of life of small-incision open cholecystectomy and laparoscopic cholecystectomy - an expertisebased randomised controlled trial. BMC Gastroenterol 2017;17:48.

28. Dancer SJ. Controlling hospital-acquired infection: focus on the role of the environment and new technologies for decontamination. Clin Microbiol Rev 2014;27:665-690.

29. Dancer SJ, White LF, Lamb J, Girvan EK, Robertson C. Measuring the effect of enhanced cleaning in a UK hospital: a prospective cross-over study. BMC Med 2009;7:28.

30. Edgcumbe DP. Patients' perceptions of hospital cleanliness are correlated with rates of meticillin-resistant Staphylococcus aureus bacteraemia. J Hosp Infect 2009;71:99-101.

31. Dubois CA, D'Amour D, Pomey MP, Girard F, Brault I. Conceptualizing performance of nursing care as a prerequisite for better measurement: a systematic and interpretive review. BMC Nurs 2013;12:7.

32. Harboe KM, Bardram L. Nationwide quality improvement of 
cholecystectomy: results from a national database. Int $\mathrm{J}$ Qual Health Care 2011;23:565-573.

33. Kow AW, Tan A, Chan SP, Lee SF, Chan CY, Liau KH, et al. An audit of ambulatory laparoscopic cholecystectomy in a Singapore institution: are we ready for day-case laparoscopic cholecystectomy? HPB (Oxford) 2008;10:433-438.

34. Ahmad NZ, Byrnes G, Naqvi SA. A meta-analysis of ambulatory versus inpatient laparoscopic cholecystectomy. Surg Endosc 2008;22:1928-1934.

35. Gregori M, Miccini M, Biacchi D, de Schoutheete JC, Bonomo L, Manzelli A. Day case laparoscopic cholecystectomy: safety and feasibility in obese patients. Int J Surg 2018;49:22-26.

36. Tan CH, Pang TC, Woon WW, Low JK, Junnarkar SP. Analysis of actual healthcare costs of early versus interval cholecystectomy in acute cholecystitis. J Hepatobiliary Pancreat Sci 2015;22:237-243.

37. Sutton AJ, Vohra RS, Hollyman M, Marriott PJ, Buja A, Alderson D, et al. Cost-effectiveness of emergency versus delayed laparoscopic cholecystectomy for acute gallbladder pathology. Br J Surg 2017;104:98-107.

38. Amirthalingam V, Low JK, Woon W, Shelat V. Tokyo Guidelines 2013 may be too restrictive and patients with moderate and severe acute cholecystitis can be managed by early cholecystectomy too. Surg Endosc 2017;31:2892-2900.

39. Lozano LM, García-Cueto E, Muñiz J. Effect of the number of response categories on the reliability and validity of rating scales. Methodology 2008;4:73-79. 
Appendix 1. PROM Questionnaire. PROM: Patient reported outcome measures

\begin{tabular}{|c|c|}
\hline Question & Answer key \\
\hline 1. What is your age range? & $\begin{array}{l}1=21-40 \text { years } \\
2=41-60 \text { years } \\
3=61-80 \text { years } \\
4=>80 \text { years }\end{array}$ \\
\hline 2. What is your gender? & $\begin{array}{l}1=\text { Male } \\
2=\text { Female } \\
3=\text { Prefer not to comment or disclose }\end{array}$ \\
\hline 3. What is your education level? & $\begin{array}{l}\text { 1=Primary school - PSLE } \\
\text { 2=Secondary school - 'O'/'N' Level } \\
\text { 3=Diploma / 'A' Level } \\
\text { 4=Degree graduate } \\
\text { 5=Degree postgraduate }\end{array}$ \\
\hline 4. What is your marital status? & $\begin{array}{l}1=\text { Single, never married } \\
2=\text { Married or partner } \\
3=\text { Widowed } \\
4=\text { Divorced or separated } \\
5=\text { Prefer not to disclose }\end{array}$ \\
\hline 5. What is your employment status? & $\begin{array}{l}1=\text { Unemployed } \\
2=\text { Self-employed } \\
3=\text { Working/Employed } \\
4=\text { Student } \\
5=\text { Retired } \\
6=\text { Homemaker } \\
7=\text { Unable to work }\end{array}$ \\
\hline 6. What is your ethnicity? & $\begin{array}{l}1=\text { Chinese } \\
2=\text { Malay } \\
3=\text { Indian } \\
4=\text { Others }\end{array}$ \\
\hline $\begin{array}{l}\text { 7. What is your type of dwelling? } \\
\text { If you stay in a HDB flat, please select the appropriate type of flat below: }\end{array}$ & $\begin{array}{l}1=\text { HDB Flat } \\
2=\text { Executive flats and others } \\
3=\text { Condominium and Private flats } \\
4=\text { Landed property } \\
5=\text { Others } \\
1=1-3 \text { room } \\
2=4-\text { room } \\
3=5 \text {-room }\end{array}$ \\
\hline 8. Do you smoke? & $\begin{array}{l}1=\text { Yes } \\
2=\text { Never } \\
3=\text { Used to, now stopped }\end{array}$ \\
\hline 9. Do you exercise? & $\begin{array}{l}1=\text { Regular } \\
2=\text { Occasional } \\
3=\text { Never }\end{array}$ \\
\hline $\begin{array}{l}\text { 10. How important is the experience level of the doctor / surgeon performing your } \\
\text { surgery? }\end{array}$ & $\begin{array}{l}1=\text { Very important } \\
2=\text { Important } \\
3=\text { Less important } \\
4=\text { Least important }\end{array}$ \\
\hline 11. How important to you is waiting time for the surgery? & $\begin{array}{l}1=\text { You prefer as soon as possible } \\
2=\text { You prefer as soon as doctor can do } \\
3=\text { Waiting time is not important to you }\end{array}$ \\
\hline $\begin{array}{l}\text { 12. After consulting the surgeon for the first time, how long had you to wait for } \\
\text { the surgery to be scheduled? }\end{array}$ & $\begin{array}{l}1=<4 \text { weeks } \\
2=4-8 \text { weeks } \\
3=8-12 \text { weeks } \\
4=>12 \text { weeks }\end{array}$ \\
\hline
\end{tabular}


Appendix 1. Continued

\begin{tabular}{|c|c|}
\hline Question & Answer key \\
\hline $\begin{array}{l}\text { 13. How important is for you that you stay under the care of same } \\
\text { Consultant doctor (senior doctor)? }\end{array}$ & $\begin{array}{l}1=\text { Very important } \\
2=\text { Important } \\
3=\text { Less important } \\
4=\text { Least important }\end{array}$ \\
\hline 14. How important to you is the pain control after surgery? & $\begin{array}{l}1=\text { Very important } \\
2=\text { Important } \\
3=\text { Less important } \\
4=\text { Least important }\end{array}$ \\
\hline 15. How good was your pain control after surgery? & $\begin{array}{l}1=\text { No pain at all } \\
2=\text { Some pain, but controlled, was within expectations } \\
3=\text { More than expected pain } \\
\begin{array}{l}4=\text { Horrible and terrifying experience, wish had not } \\
\text { undergone the surgery }\end{array}\end{array}$ \\
\hline $\begin{array}{l}16 \text { How important to you is each of the following aspect of your } \\
\text { a. Duration of the procedure }\end{array}$ & $\begin{array}{l}\text { procedure? } \\
1=\text { Very important } \\
2=\text { Important } \\
3=\text { Less important } \\
4=\text { Least important }\end{array}$ \\
\hline b. Successful key hole surgery & $\begin{array}{l}\text { 1=Very important } \\
2=\text { Important } \\
3=\text { Less important } \\
4=\text { Least important }\end{array}$ \\
\hline c. Amount of blood loss & $\begin{array}{l}\text { 1=Very important } \\
2=\text { Important } \\
3=\text { Less important } \\
\text { 4=Least important }\end{array}$ \\
\hline d. Overall risk of complications & $\begin{array}{l}\text { 1=Very important } \\
2=\text { Important } \\
3=\text { Less important } \\
\text { 4=Least important }\end{array}$ \\
\hline e. Risk of severe complications & $\begin{array}{l}1=\text { Very important } \\
2=\text { Important } \\
3=\text { Less important } \\
4=\text { Least important }\end{array}$ \\
\hline f. Risk of minor complications & $\begin{array}{l}1=\text { Very important } \\
2=\text { Important } \\
3=\text { Less important } \\
4=\text { Least important }\end{array}$ \\
\hline g. Risk of bile leak & $\begin{array}{l}\text { 1=Very important } \\
2=\text { Important } \\
3=\text { Less important } \\
4=\text { Least important }\end{array}$ \\
\hline h. Risk of bile duct injury & $\begin{array}{l}1=\text { Very important } \\
2=\text { Important } \\
3=\text { Less important } \\
4=\text { Least important }\end{array}$ \\
\hline i. Risk of retained stone within & $\begin{array}{l}1=\text { Very important } \\
2=\text { Important } \\
3=\text { Less important } \\
4=\text { Least important }\end{array}$ \\
\hline j. Risk of anaesthesia & $\begin{array}{l}1=\text { Very important } \\
2=\text { =Important } \\
3=\text { Less important } \\
4=\text { Least important }\end{array}$ \\
\hline
\end{tabular}


Appendix 1. Continued

\begin{tabular}{|c|c|}
\hline Question & Answer key \\
\hline $\begin{array}{l}\text { 17. How important to you are the following aspect of recovery process? } \\
\text { a. Going home on same day }\end{array}$ & $\begin{array}{l}1=\text { Very important } \\
2=\text { Important } \\
3=\text { Less important } \\
4=\text { Least important }\end{array}$ \\
\hline b. Going home the next day & $\begin{array}{l}1=\text { Very important } \\
2=\text { Important } \\
3=\text { Less important } \\
4=\text { Least important }\end{array}$ \\
\hline c. Short time to recovery of normal function e.g. doing daily activities & $\begin{array}{l}1=\text { Very important } \\
2=\text { Important } \\
3=\text { Less important } \\
4=\text { Least important }\end{array}$ \\
\hline d. Shorter period of medical leave & $\begin{array}{l}1=\text { Very important } \\
2=\text { Important } \\
3=\text { Less important } \\
4=\text { Least important }\end{array}$ \\
\hline e. Shorter time before returning to normal diet & $\begin{array}{l}1=\text { Very important } \\
2=\text { Important } \\
3=\text { Less important } \\
4=\text { Least important }\end{array}$ \\
\hline f. Cost of the hospital stay/procedure & $\begin{array}{l}1=\text { Very important } \\
2=\text { Important } \\
3=\text { Less important } \\
4=\text { Least important }\end{array}$ \\
\hline $\begin{array}{l}\text { 18. How important to you are the following elements of overall hospital experience? } \\
\text { a. Your involvement in the decision making }\end{array}$ & $\begin{array}{l}1=\text { Very important } \\
2=\text { Important } \\
3=\text { Less important } \\
4=\text { Least important }\end{array}$ \\
\hline b. Communication skill of the doctor/surgeon & $\begin{array}{l}1=\text { Very important } \\
2=\text { Important } \\
3=\text { Less important } \\
4=\text { Least important }\end{array}$ \\
\hline c. Technical skill/Surgical skill of the doctor/surgeon & $\begin{array}{l}1=\text { Very important } \\
2=\text { Important } \\
3=\text { Less important } \\
4=\text { Least important }\end{array}$ \\
\hline d. Dietary advice before and after the doctor/surgeon & $\begin{array}{l}1=\text { Very important } \\
2=\text { Important } \\
3=\text { Less important } \\
4=\text { Least important }\end{array}$ \\
\hline e. Reputation of the doctor/surgeon performing your surgery & $\begin{array}{l}\text { 1=Very important } \\
2=\text { Important } \\
3=\text { Less important } \\
4=\text { Least important }\end{array}$ \\
\hline f. Cleanliness of the ward/theatre area & $\begin{array}{l}1=\text { Very important } \\
2=\text { Important } \\
3=\text { Less important } \\
4=\text { Least important }\end{array}$ \\
\hline g. Standards of the nursing care & $\begin{array}{l}1=\text { Very important } \\
2=\text { Important } \\
3=\text { Less important } \\
4=\text { Least important }\end{array}$ \\
\hline
\end{tabular}


Appendix 1. Continued

\begin{tabular}{|c|c|}
\hline Question & Answer key \\
\hline h. Standards of hospital food & $\begin{array}{l}1=\text { Very important } \\
2=\text { Important } \\
3=\text { Less important } \\
4=\text { Least important }\end{array}$ \\
\hline i. Opinion of friends and family about the hospital & $\begin{array}{l}1=\text { Very important } \\
2=\text { Important } \\
3=\text { Less important } \\
4=\text { Least important }\end{array}$ \\
\hline j. Hospital provides you the contact details of the ward after discharge & $\begin{array}{l}\text { 1=Very important } \\
2=\text { Important } \\
3=\text { Less important } \\
4=\text { Least important }\end{array}$ \\
\hline $\begin{array}{l}\text { 19. How important to you are the following aspects of long-term outcomes? } \\
\text { a. Cosmetic appearance of the scar }\end{array}$ & $\begin{array}{l}1=\text { Very important } \\
2=\text { Important } \\
3=\text { Less important } \\
4=\text { Least important }\end{array}$ \\
\hline b. Residual abdominal symptoms after the procedure & $\begin{array}{l}\text { 1=Very important } \\
2=\text { Important } \\
3=\text { Less important } \\
4=\text { Least important }\end{array}$ \\
\hline c. Overall satisfaction with the procedure & $\begin{array}{l}1=\text { Very important } \\
2=\text { Important } \\
3=\text { Less important } \\
4=\text { Least important }\end{array}$ \\
\hline d. Quality of life after surgery & $\begin{array}{l}1=\text { Very important } \\
2=\text { Important } \\
3=\text { Less important } \\
4=\text { Least important }\end{array}$ \\
\hline
\end{tabular}

